\title{
QUALIDADE DA EDUCAÇÃO BÁSICA: \\ DAS POLÍTICAS PÚBLICAS ÀS EXPECTATIVAS DOS PROFESSORES ${ }^{*}$
}

\author{
QUALITY OF BASIC EDUCATION: \\ FROM PUBLIC POLICY TO TEACHERS' EXPECTATIONS
}

Abdeljalil Akkari, da Haute École Pédagogique, BEJUNE (Suiça). Rossana Valéria Souza Silva Ana Sheila Fernandes Costa, da Universidade Federal de Uberlândia.

\section{RESUMO}

Este artigo apresenta alguns resultados de um projeto de pesquisa conjunto entre a HEPBEJUNE e diferentes instituições brasileiras. Inicialmente, analisamos o contexto nacional e internacional dentro do qual se situa a Educação Básica no Brasil. Em seguida, apresentamos o uso da noção de qualidade em educação. Para finalizar, apresentamos alguns resultados da pesquisa de campo realizada com professores que atuam em escolas públicas nos estados de Goiás e Minas Gerais.

Palavras-chave: Educação Básica. Qualidade. Professores. Escolas Púbicas.

\section{INTRODUÇÃO}

O presente artigo relata os resultados da pesquisa intitulada $O$ papel da formação e do trabalho docente na qualidade da educação básica nos estados de Minas Gerais e Goiás, realizada como parte das atividades previstas no Acordo de Cooperação entre a Haute École Pédagogique - BEJUNE e a Universidade Federal de Uberlândia. A pesquisa foi financiada pela Conférence des Recteurs des Hautes Ecoles Spécialisées Suisses (KFH) dentro do programa Research Partnerships between Swiss Universities of Applied Sciences and Developping and Transition Countries (KFH, Suíça).

A pesquisa teve como objetivo geral analisar a qualidade da educação básica nos Estados de Minas Gerais e Goiás e compará-la com parâmetros nacionais e internacionais. Mais especificamente, buscou:

a) investigar a opinião dos professores sobre as dimensões que contribuem para a qualidade da Educação Básica;

b) verificar em que medida as mudanças realizadas no âmbito das políticas públicas no Brasil, nas últimas duas décadas, estão materializadas no trabalho cotidiano do professor.

Ao todo, foram pesquisadas seis escolas, cinco em Minas Gerais e uma em Goiás. 
EdUCAÇÃO BÁSICA NO BRASIL: AS REFORMAS EDUCACIONAIS E AS DIMENSÕES DA QUALIDADE

A atual configuração da Educação Básica brasileira reflete, em grande medida, as mudanças desencadeadas pelas reformas dos anos de 1990. A partir da implementação de políticas econômicas e educacionais de ajuste, o governo brasileiro intentou a modernização e consequente inserção do país no mundo globalizado, com vistas a ajustá-lo às exigências estabelecidas por instituições financeiras e corporações internacionais.

Nos anos de 1990, a Educação Básica ganhou destaque em nível mundial, por ocasião da Conferência Mundial de Educação para Todos, Jomtien - Tailândia. Essa conferência, convocada pelo Banco Mundial, UNESCO, UNICEF e PNUD ${ }^{1}$, provocou na América Latina e em outras regiões do mundo um impulso para ações que contribuíram para a centralização da educação básica nas políticas educacionais de diversos países.

Conforme Oliveira (2006), as reformas educacionais dos anos de 1990 tiveram como orientação principal a equidade social. A formação para o emprego formal e regulamentado passou a ser um imperativo dos sistemas escolares, ao mesmo tempo em que aquelas deveriam desempenhar um papel na condução de políticas sociais de cunho compensatório que, em outras palavras, apontassem para a contenção da pobreza: a educação dirigida à formação para o trabalho e a educação voltada para a gestão e o disciplinamento da pobreza.

Uma nova forma de regulação evidenciada pela centralidade atribuída à administração escolar nos programas de reforma, repercutiu na composição, estrutura e gestão das redes públicas de ensino. Foram implementadas medidas que alteraram a configuração das redes em seus aspectos físicos e organizacionais forjando a educação segundo os critérios de produtividade, eficácia, excelência e eficiência, presentes nos programas de reforma.

A partir da aprovação da Lei de Diretrizes e Bases da Educação Nacional LDB 9.394/96, uma série de alterações foi efetivada, novas propostas de gestão da educação, de financiamento, de programas de avaliação educacional, de políticas de formação de professores, dentre outras medidas, foram realizadas no sentido de melhorar a qualidade da educação. Três dimensões da educação receberam grande enfoque: a estrutura, o currículo e a gestão. (GARCIA; ANADON, 2006)

A Educação Básica passou a ser composta pela Educação Infantil, Ensino Fundamental e Ensino Médio, com o objetivo assegurar a todos os brasileiros uma formação comum indispensável ao exercício da cidadania bem como garantir os meios que possibilitem a progressão no trabalho e em estudos posteriores. (BRASIL, 1996)

Destacamos ainda os Parâmetros Curriculares Nacionais (PCN) com a definição de conteúdos curriculares mínimos para os estabelecimentos de ensino de todo o país. As avaliações nacionais com o objetivo de diagnosticar os resultados da educação brasileira por meio de exames nacionais padronizados, como o Sistema Nacional de Avaliação da Educação Básica (SAEB) e o Exame Nacional do Ensino Médio (ENEM). No concernente ao financiamento da Educação Básica, evidenciamos a criação do 
Fundo de Manutenção e Desenvolvimento do Ensino Fundamental e de Valorização do Magistério (FUNDEF), substituído em 2007 pelo Fundo de Manutenção e Desenvolvimento da Educação Básica e de Valorização dos Profissionais da Educação (FUNDEB).

Também merece destaque a criação, por parte do Ministério da Educação, do Índice de Desenvolvimento da Educação Básica (IDEB) com o objetivo de mensurar e acompanhar os progressos do índice de desenvolvimento da educação básica nas diferentes esferas administrativas: federal, estadual e municipal. Esse índice pode variar de zero a dez e o nível seis tem indicado o nível de educação de base encontrado nos sistemas escolares em âmbito internacional.

Nesse contexto, a discussão acerca dos critérios definidores da qualidade da educação implica na necessidade de se mapearem algumas dimensões que traduzem, no campo das políticas públicas e no contexto escolar, os elementos definidores da qualidade educacional.

\section{ASPECTOS METODOLÓGICOS}

No intuito da realização da pesquisa, definimos alguns critérios, etapas e procedimentos básicos para o processo de coleta e análise dos dados. Ao todo, foram pesquisadas seis escolas, no estado de Minas Gerais e no estado de Goiás.

No estado de Minas Gerais, uma escola faz parte de uma rede municipal de ensino, três, da rede estadual e uma, da rede privada. No estado de Goiás, investigamos uma escola de uma rede municipal de ensino. Dentre as escolas selecionadas, duas situam-se na zona rural e quatro, na zona urbana, conforme expresso no quadro abaixo.

Quadro 1 - Escolas por regiões, estado e sua distribuição por localização e dependência administrativa

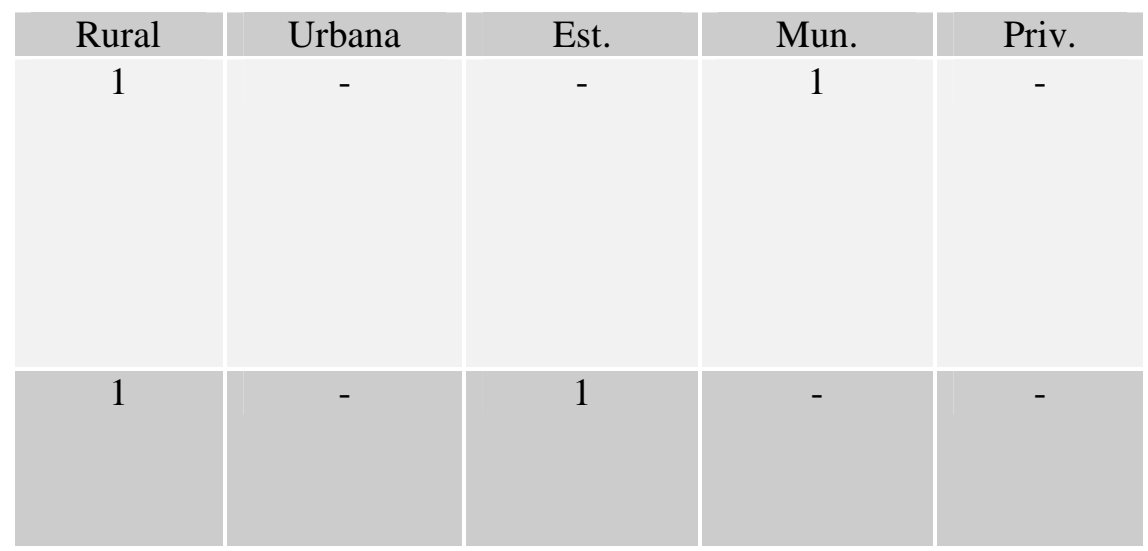




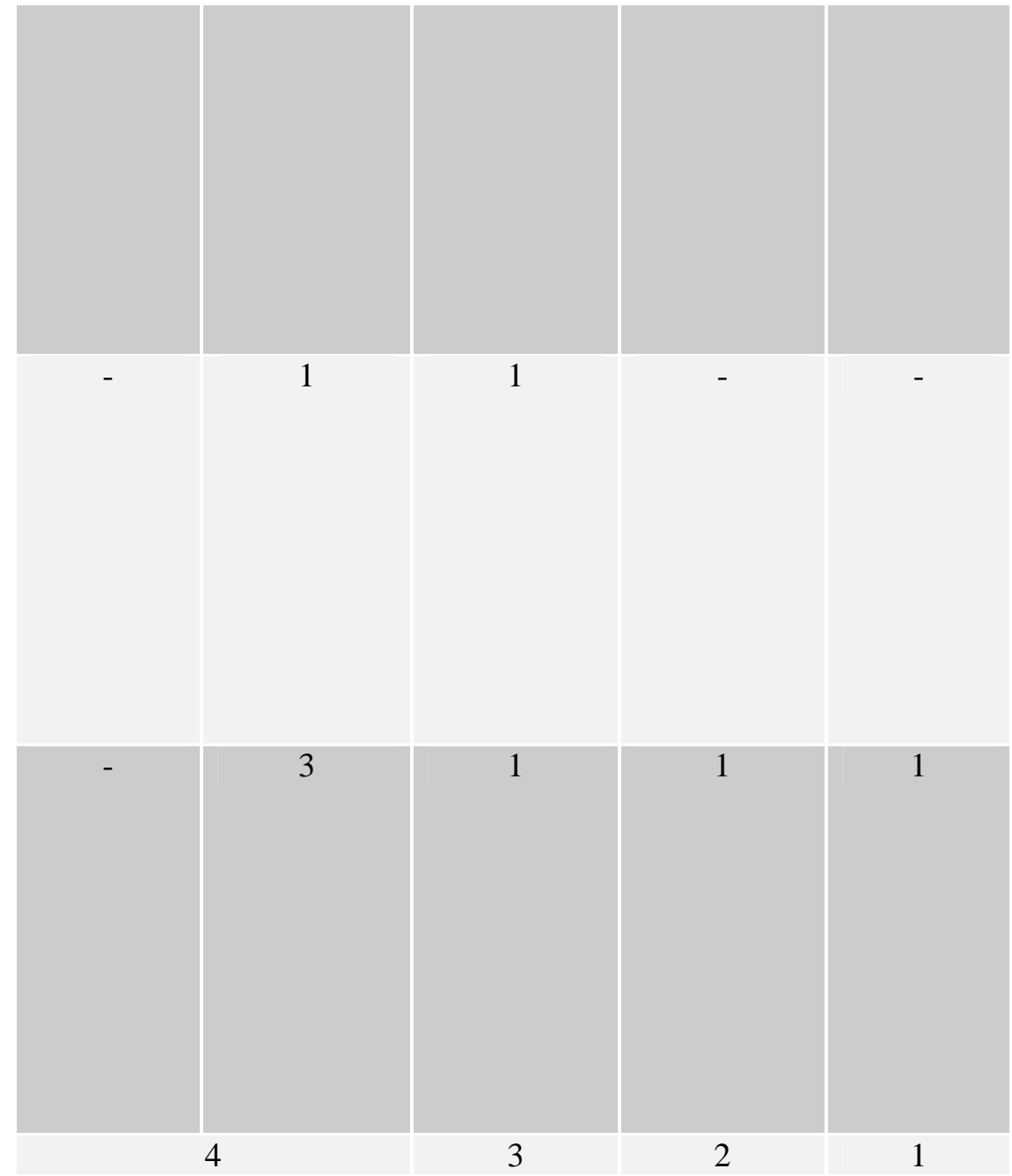

A escola municipal 1 localiza-se na cidade de Uberlândia, em Minas Gerais, e funciona em dois turnos, atendendo alunos da Educação infantil e das séries iniciais do Ensino Fundamental. Por ocasião do levantamento dos dados da pesquisa possuía 610 alunos e 20 professores.

A escola municipal 2 localiza-se na Zona Rural da cidade de Catalão, em Goiás, e é constituída por 82 alunos e oito professores.

A escola estadual 1 localiza-se na cidade de Uberlândia, atende a alunos do Ensino Fundamental e possui 690 alunos e 55 professores.

A escola estadual 2 está localizada na cidade de Ituiutaba, também em Minas Gerais, e também atende alunos do Ensino Fundamental. Essa escola possui 660 alunos e 55 professores.

No que diz respeito à escola estadual 3, está localizada na zona rural do município de Iraí de Minas, possui 78 alunos e oito professores e atende alunos do ensino fundamental.

A escola da rede privada 1 está localizada na cidade de Uberlândia, atende alunos do ensino fundamental e possui 268 alunos e 29 professores. 
A pesquisa constituiu-se de dois momentos. No primeiro, analisamos a perspectiva do professor sobre a qualidade da educação básica no Estado de Minas Gerais e no Estado de Goiás e o segundo destinou-se ao levantamento de estudos relativos à qualidade da Educação Básica.

Para a coleta de dados junto aos professores da Educação Básica, um dos procedimentos adotados foi a realização de entrevistas, com professores e diretores. Entrevistamos vinte e quatro professores e quatro diretores de escolas, de acordo com a distribuição abaixo:

Escola municipal 1: quatro professores

Escola municipal 2: três professores e um diretor

Escola estadual 1: cinco professores e um diretor

Escola estadual 2: três professores

Escola estadual 3: cinco professores e um diretor

Escola da rede privada 1: quatro professores e um diretor

As entrevistas, do tipo entrevista aberta, foram realizadas em maio de 2008 e tiveram duração entre trinta a quarenta minutos.

Os principais eixos orientadores das entrevistas com os professores foram: a) os motivos da escolha da profissão; b) a qualidade do ensino na escola onde trabalham; c) o papel do professor na melhoria da qualidade da educação; d) a importância dos recursos materiais; e) a importância da colaboração família-escola; f) a importância do reconhecimento do papel do professor por parte da sociedade; g) os métodos pedagógicos mais utilizados em sala de aula e h) a importância do projeto político pedagógico e sua contribuição para a qualidade da educação.

A entrevista com os diretores das escolas, além das dimensões supracitadas, contemplou questões sobre as características de organização e funcionamento das escolas. Dentre os aspectos levantados, destacamos: (1) localização e dependência administrativa das unidades escolares; (2) número de alunos matriculados; (3) número de docentes; (4) o valor das mensalidades, no caso das escolas privadas; (5) o salário médio dos professores; (6) infra-estrutura existente nos prédios escolares; e (7) a existência de Projeto Político Pedagógico.

Para a realização das entrevistas, obtivemos a autorização do diretor, ou da diretora, de cada escola. Os critérios para seleção dos professores foram: a) a indicação do diretor da escola; b) a disponibilidade do professor e c) a concordância e o interesse demonstrado em contribuir com o estudo.

Todas as entrevistas foram gravadas e transcritas na íntegra. Posteriormente, foram organizadas em oito itens, conforme os seguintes critérios:

1) a escolha da profissão;

2) a qualidade da escola;

3) a qualidade da educação nas diferentes redes de ensino;

4) a importância do Projeto Político Pedagógico;

5) a contribuição dos métodos pedagógicos para a qualidade da educação;

6) a colaboração família e da escola;

7) a imagem e o reconhecimento da profissão de professor;

8) as prioridades para a melhoria da educação pública. 
Outro procedimento de coleta de dados adotado foi o registro fotográfico das escolas, realizado com o intuito de melhor captar suas estruturas físicas.

Além disso, foram coletados dados junto à Secretaria Estadual de Educação de Minas Gerais e ao Instituto Nacional de Estudos e Pesquisas Educacionais Anísio Teixeira - INEP.

\section{PRINCIPAIS RESULTADOS}

Os dados apresentados, fornecidos pelas Secretarias Estaduais de Educação, quando comparados aos dados apresentados pelas escolas possibilita-nos perceber que: a) em relação ao número de matrículas, verifica-se que o estado de Minas Gerais, nas escolas pesquisadas da rede estadual urbana de Ituiutaba e de Uberlândia, registrou o maior número (642 e 592, respectivamente), enquanto o menor número ocorreu na rede na escola rural da rede municipal de Catalão, no Estado de Goiás (69).

Ao confrontarmos esses dados com os encontrados no ano de 2008, por ocasião da realização da pesquisa, verificamos um aumento, nesses números, nas escolas em geral, com destaque para a rede estadual urbana de Ituiutaba e de Uberlândia, que ampliaram o número de matrículas de 642 e 592 para 660 e 690, respectivamente. Somente a escola estadual rural de Iraí de Minas teve redução do número de matrículas em relação ao ano de 2007, passando de 95 para 78 matrículas.

b) Em relação ao número de professores, verificamos um número maior nas escolas da rede estadual e, ao comparamos o número de professores nos anos de 2007 e 2008, percebemos uma redução no quadro de professores nas escolas da rede municipal, tendo havido, em contrapartida, aumento significativo na rede estadual de ensino.

c) No que diz respeito ao pessoal técnico e administrativo, percebemos certa equivalência entre as escolas da rede urbana. Somente na escola da zona rural de Irai de Minas, encontramos uma grande discrepância em relação às escolas investigadas. Enquanto as escolas da zona urbana possuem. em média, 21 funcionários, a escola da zona rural apresenta um quadro de apenas seis funcionários.

De modo geral, verifica-se que as relações mais altas entre o número de matrículas, número de docentes e número de funcionários, encontram-se na esfera estadual urbana, seguida da esfera municipal urbana e da zona rural. Fato que pode ser explicado pela maior atuação dos estados nos anos finais do Ensino Fundamental e no Ensino Médio, que exigem maior número de professores e de funcionários.

A relação entre o número de matrículas e o número de docentes tende a ser maior em escolas que oferecem todas ou quase todas as etapas da Educação Básica, como é o caso das escolas estaduais, sobretudo daquelas de Educação Profissional, Ensino Médio, EJA e escolas de quinta a oitava séries do ensino fundamental. Por outro lado, essa relação tende a ser menor nas escolas municipais. Em geral, observa-se que a relação média entre o número de professores e alunos é alta em especial na escola da rede municipal urbana, o que pode trazer implicações negativas para a qualidade do processo ensino-aprendizagem.

Os dados apresentados na Tabela 1 permitem visualizar a dependência administrativa, o número de matrículas, de docentes e de funcionários das escolas pesquisadas. 
Tabela 1: As relações entre matrículas, docentes e funcionários técnicos administrativos e de apoio, por tipo de escola e dependência administrativa. 
Fonte: SEE-MG/SI/SIE/Dir. de informações educacionais. Dados do Censo Escolar de 2007 SIEDMG

*Dados fornecidos pelos diretores das escolas investigadas no ano de 2008.

Analisamos, ainda, junto ao INEP, o Índice de Desenvolvimento da Educação Básica (IDEB) das escolas que compuseram a amostra de nossa pesquisa, a partir do cálculo do IDEB realizado no ano de 2007 em 48.497 escolas distribuídas nos 5.533 municípios brasileiros. Os resultados de cada escola, município ou unidade da Federação foram calculados a partir do desempenho obtido pelos alunos que participaram da Prova Brasil, do Saeb, e das taxas de aprovação globais, calculadas a partir das informações presentes no Censo Escolar.

No Tabela 2 , apresentamos o IDEB do Ensino Fundamental (anos inicias e finais) e Ensino Médio em nível nacional, apurado nos anos de 2005 e 2007, na dependência administrativa pública federal, na pública estadual e na pública municipal bem como na rede privada e os índices projetados para essas redes de ensino brasileiras.

Os índices do Ensino fundamental apresentados em 2007 nos permitem verificar que as metas projetadas para esse ano foram atingidas em quase sua plenitude. Os maiores índices foram observados na rede federal de ensino, que não apresentou grandes diferenças tanto nos anos iniciais $(6,2)$ quanto nos finais do ensino fundamental $(6,1)$. Todavia, quando comparamos índices gerais da rede pública e privada de ensino, os dos anos iniciais e finais do Ensino Fundamental (6,0 e 5,8 respectivamente) aparecem mais altos em relação ao da rede pública $(4,0$ e 3,5).

Em relação às redes municipais e estaduais brasileiras, os índices mais altos foram encontrados nos anos iniciais do Ensino Fundamental, 4,3 e 4,0 respectivamente. Enquanto que anos finais foram de 3,6 e 3,4.

O IDEB observado no Ensino Médio reflete, em grande medida, os índices revelados nas redes de ensino brasileiras, ou seja, os maiores índices foram encontrados na rede federal e na rede privada de ensino (5,7 e 5,6 respectivamente), seguidas pelas redes estaduais e municipais (3,2, em ambas.); entretanto, os índices encontrados nesse nível de ensino são inferiores aos índices do Ensino Fundamental. 
Tabela 2: Índice de Desenvolvimento da Educação Básica 2005 e 2007 e projeções para o Brasil

\begin{tabular}{|c|c|c|c|c|c|c|c|c|c|c|c|c|}
\hline & \multicolumn{4}{|c|}{$\begin{array}{c}\text { Anos Iniciais do Ensino } \\
\text { Fundamental }\end{array}$} & \multicolumn{4}{|c|}{$\begin{array}{l}\text { Anos Finais do Ensino } \\
\text { Fundamental }\end{array}$} & \multicolumn{4}{|c|}{ Ensino Médio } \\
\hline & \multicolumn{2}{|c|}{$\begin{array}{c}\text { IDEB } \\
\text { Observado }\end{array}$} & \multicolumn{2}{|c|}{ Metas } & \multicolumn{2}{|c|}{$\begin{array}{c}\text { IDEB } \\
\text { Observado }\end{array}$} & \multicolumn{2}{|c|}{ Metas } & \multicolumn{2}{|c|}{$\begin{array}{c}\text { IDEB } \\
\text { Observado }\end{array}$} & \multicolumn{2}{|c|}{ Metas } \\
\hline & 2005 & 2007 & 2007 & 2021 & 2005 & 2007 & 2007 & 2021 & 2005 & 2007 & 2007 & 2021 \\
\hline TOTAL & 3,8 & 4,2 & 3,9 & 6,0 & 3,5 & 3,8 & 3,5 & 5,5 & 3,4 & 3,5 & 3,4 & 5,2 \\
\hline \multicolumn{13}{|c|}{ Dependência Administrativa } \\
\hline Pública & 3,6 & 4,0 & 3,6 & 5,8 & 3,2 & 3,5 & 3,3 & 5,2 & 3,1 & 3,2 & 3,1 & 4,9 \\
\hline Federal & 6,4 & 6,2 & 6,4 & 7,8 & 6,3 & 6,1 & 6,3 & 7,6 & 5,6 & 5,7 & 5,6 & 7,0 \\
\hline Estadual & 3,9 & 4,3 & 4,0 & 6,1 & 3,3 & 3,6 & 3,3 & 5,3 & 3,0 & 3,2 & 3,1 & 4,9 \\
\hline Municipal & 3,4 & 4,0 & 3,5 & 5,7 & 3,1 & 3,4 & 3,1 & 5,1 & 2,9 & 3,2 & 3,0 & 4,8 \\
\hline Privada & 5,9 & 6,0 & 6,0 & 7,5 & 5,8 & 5,8 & 5,8 & 7,3 & 5,6 & 5,6 & 5,6 & 7,0 \\
\hline
\end{tabular}

Fonte: INEP 2008

No concernente aos índices dos estados pesquisados, verificamos que, apesar de Minas Gerais apresentar índice mais alto (4,7), não há grande diferença do índice encontrado em Goiás $(4,3)$. Em relação às escolas pesquisadas, verificamos que os maiores índices foram encontrados nos anos iniciais do Ensino Fundamental, dentre os quais a escola da rede estadual urbana de Ituiutaba apresentou o maior índice $(5,9)$, seguida pelas escolas da rede municipal $(5,1)$ e da estadual $(4,7)$ de Uberlândia, conforme demonstrado no quadro 4.

Tabela 3: IDEB observado e projetado das escolas pesquisadas por cidade, dependência administrativa e nível de ensino. 



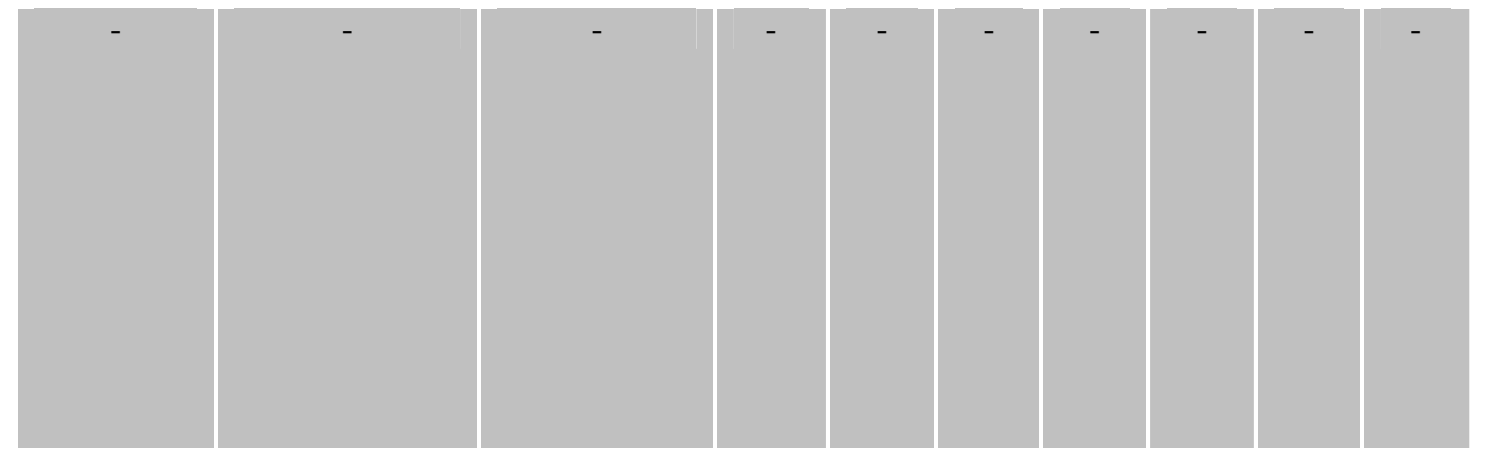

Fonte: INEP 2008

*Ideb não disponível no INEP ${ }^{2}$

Os índices demonstrados acima se configuram como um dos critérios que avaliam a qualidade da educação e que servem para ratificar a proposição de que os níveis de qualidade da educação ainda são mais altos em escolas da zona urbana e em escolas da rede privada de ensino.

A QUALIDADE DA EDUCAÇÃO BÁSICA NA PERCEPÇÃO DOS PROFESSORES DA REDE PÚBLICA E PARTICULAR DE ENSINO

a) A escolha da profissão

A análise sobre os motivos que levaram à escolha da profissão permitiu-nos constatar que para, muitos professores, essa profissão de professor não é necessariamente resultado de uma escolha, mas fruto de circunstâncias particulares ou mesmo da falta de outras opções mais valorizadas. Nesse sentido, pudemos observar três principais tipos de trajetórias que conduziram à profissão de professor. A primeira diz respeito a uma vocação precoce; a segunda, à falta de opção; a terceira, à 
necessidade de uma segunda profissão ou a uma escolha tardia. Temos, ainda, um pequeno grupo de professores que afirmam dever-se a escolha da profissão a influencia da família. visto que havia nela alguns membros que já exerciam essa profissão.

Foi vocação mesmo! Essa já veio desde criança, eu dava aula até para as bonecas, como se diz, o instinto mesmo de vocação. (ENTREVISTADA 2)

A minha escolha é porque eu amo de paixão dar aula e eu me sinto muito gratificada quando eu consigo transmitir um pouco do que eu sei para os meus alunos e assim, além do mais, eu acho assim que o professor de certa forma é um formador de opinião, e os profissionais desta área eles têm que dar aula por paixão porque se for olhar pelo aspecto financeiro ele tem que casar bem para executar a função por prazer. (ENTREVISTADA 12)

Foi por vocação mesmo, desde criança gostei muito, foi vocação e não acidente. (ENTREVISTADA 23)

Alguns professores relataram que, apesar da falta de vocação, quando começaram a lecionar, foram se apaixonando pela profissão e hoje não se imaginam em outra profissão. Entretanto, há aqueles que são questionados pela própria família pela escolha da profissão de professor, fato que desperta um sentimento de culpa e de insucesso pela opção feita por parte desses professores.

Eu não escolhi, foi o único curso que tinha segundo grau era o magistério, não queria fazer de forma alguma, minha mãe disse que eu tinha que fazer. A escola era muito bonita, de freira e daí eu fiz. Ao terminar o magistério comecei a fazer serviço social na zona rural e daí eu me interessei pela população, mas eu não escolhi ser professora. (ENTREVISTADA 24)

Primeiramente, foi uma falta de oportunidade de trabalho que tinha na minha região; antigamente ou a mulher era professora ou dona-de-casa Eu prefiro ser professora [...] a escola foi a única opção que eu tive. (ENTREVISTADA 25)

No que diz respeito à formação dos professores entrevistados, grande parte cursou o magistério e imediatamente começou a lecionar. A partir das exigências da Lei de Diretrizes e Bases (LDB), a maioria desses professores, que já atuava no ensino, fez o curso de graduação a fim de atender às novas exigências determinadas pela legislação.

Nessa perspectiva, constatamos que a maioria dos professores entrevistados possui formação no ensino superior e já fizeram curso de pós-graduação lato-Sensu. O quadro de professores investigados apresenta a seguinte formação inicial: Pedagogia (11), Letras (2), Licenciatura Curta em Ciências (3), Ciências Biológicas (2), Geografia (2), Matemática (2), Psicologia (1), Filosofia (1), Educação Física (1), Serviço Social (1), Ciências Sociais (1) e Normal Superior (1).

Uma parte considerável realizou tanto os estudos de graduação quanto de pósgraduação em instituições privadas de Ensino Superior, fato em grande medida explicado pela falta de condições financeiras de deslocar-se para outras cidades a fim de realizar os estudos e, ao mesmo tempo, pela exigência de especializar-se.

Quando indagados se a formação que receberam contribuiu para a qualidade do ensino que oferecem, há algumas divergências quanto a essa contribuição. Para os professores que já tinham o magistério, experiência sala-de-aula e depois fizeram curso superior, a formação acadêmica recebida contribuiu muito para o trabalho em sala de 
aula, como aponta uma professora de 40 anos e 17 anos no exercício do magistério, que atua na rede particular e municipal: "contribui muito, demais, em todos os sentidos, precisa do embasamento teórico para dar suporte à prática" (ENTREVISTADA 7)

Entretanto, alguns professores percebem uma desconexão entre a formação acadêmica e o trabalho cotidiano. Afirmam que só a teoria desvinculada da prática não tem sentido e que, na maioria das vezes, são os cursos de formação continuada e capacitação que ajudam a suprir as lacunas deixadas por essa formação, como podemos verificar no depoimento de uma professora de 30 anos. com 10 de exercício profissional.

Não, A formação acadêmica contribui pouco, muito longe da realidade que tem em sala de aula. A formação que tenho foi muito mais como curso de capacitação do que curso de pedagogia; é muito mais pratico do que o curso de pedagogia. O curso de pedagogia para prática em sala de aula [ajuda] quase nada, [fica] muito longe, fica muito na teoria. Amplia o horizonte como profissional, estuda autores, momentos da educação do país mas a realidade dos meus alunos aprendi fora nos cursos no dia-a- dia. (ENTREVISTADA 8)

O que ensina na faculdade é uma coisa e o que você trabalha na realidade é outra, completamente diferente. Porque lá a gente vê a parte teórica, o professor ensina a teoria prá gente. A maneira de dar aula, isso aí você adquire com sua prática, com habilidade. [...] Eu sei que a realidade da escola é uma e o que ensina na faculdade, não; é bem outra. Tem um parâmetro, mas, assim, tem uma diferença, é diferente, ajuda pouco; ela deveria trabalhar mais a forma da gente entrar na sala de aula, de trabalhar com o aluno. Isso é uma grande dificuldade que a gente tem. (ENTREVISTADA 2)

Quando questionados sobre o poder do professor na melhoria da qualidade da educação, os professores foram unânimes afirmando que sim, que o professor tem poder e importante papel na melhoria da qualidade da educação. Apontaram, contudo, que esse poder não depende só deles, mas de que sejam criadas condições para que ele possa exercer seu papel nessa melhoria, o que inclui a valorização do professor, melhores salários, mais recursos para a escola, maior colaboração dos pais e, finalmente, maior apoio por parte do governo.

b) A qualidade da escola

Ao serem solicitados a avaliarem a qualidade da educação na escola onde trabalham, verificamos algumas divergências caracterizadas entre as escolas públicas e escolas privadas. $\mathrm{Na}$ rede privada, os entrevistados foram unânimes em apontar a qualidade do ensino em sua escola em relação a outras redes. A maioria dos professores (que também possuem um cargo na rede pública) opta pela escolarização de seus filhos na rede privada. Os poucos professores que, em algum momento, optaram pelo ensino público o fizeram por falta de recursos financeiros.

Há um consenso, tanto na rede pública quanto na rede privada, sobre a importância dos recursos materiais para a qualidade da educação. $\mathrm{Na}$ escola privada, essa necessidade é apresentada com ênfase em vista da possibilidade de ministrar aulas 
mais interessantes, com materiais diversificados, uma vez que a escola já possui uma boa infra-estrutura e os recursos seriam para o melhoramento das aulas.

No entanto, nas escolas públicas, percebemos que esses recursos são necessários, antes de qualquer coisa, para a sobrevivência das escolas. Verificamos nessas escolas uma grande carência de recursos, em especial nas escolas da zona rural, para as quais os recursos enviados são insuficientes no sentido de suprir suas necessidades; muitas vezes, a escola tem que buscar outras fontes de recursos, apelando para os pais e para a própria comunidade, como demonstrado no depoimento da professora da rede estadual, há 27 anos no ensino e dez na direção.

Muito importante, a escola pública recebe pouco recurso. Na escola pública, o recurso que vem não é suficiente para manter a escola, nem para o lanche, nem com material e o que vem aqui eu gasto com os próprios alunos, as verbas que vêm é para manter o mínimo possível e a gente trabalha muito com recurso assim: você pede ajuda para outras pessoas, pra comunidade. Não pede tanto, pois não têm muitos recursos e também é uma comunidade pobre, mas a gente vai e anda atrás, mas o que vem dos órgãos públicos é muito pouco; tanto os salários dos professores - eu acho que uma das maiores desmotivações que os professores tem é justamente o baixo salário porque [n]o ensino público em Minas Gerais e no Brasil de modo geral os recursos são poucos. (ENTREVISTADA 1)

c) A qualidade da educação nas diferentes redes de ensino

Tratando-se especificamente dos depoimentos dos professores da rede pública, estes avaliam que a educação é boa, mas que tem muito a melhorar. Verificamos que apesar das restrições para realizarem seu trabalho alguns são muito empenhados em melhorar a qualidade do ensino em sua escola. Entretanto, quando questionados sobre a rede de ensino que tem qualidade a grande maioria afirma que essa qualidade e encontrada na rede particular e que seus filhos só não vão para essas escolas por falta de recursos.

Observamos, entre os professores da rede pública, uma grande tensão entre a "vontade de melhorar" a qualidade do ensino público e "a escolha do privado" para a escolarização de seus próprios filhos.

Escola particular... Manteria meu filho na escola pública porque dá mais vivência, só colocaríamos na particular porque ela prepara, em termos de conteúdo para ingressar entrar na faculdade pública. Para os filhos estarem na universidade pública, eles tem que estar, hoje, na escola particular, pois ela tem mais conteúdo e prepara melhor o aluno. Acreditamos na vivencia da escola pública, mas para ingressar na faculdade pública é preciso ir para a particular [...]. Eu acredito e invisto na escola pública, meu coração é da escola pública. Fazemos debates, mas não conseguimos ser ouvidos. (ENTREVISTADO 12)

Acho que o particular está mostrando que tem mais qualidade a gente vê isso quando têm as avaliações; então as avaliações é que estão mostrando pra gente que a qualidade está na escola particular porque são poucas escolas públicas que estão encabeçando as listas das escolas que estão saindo bem nas avaliações externas [...] Olha quem tem 
renda mais alta coloca na escola particular automaticamente agora se ele não pode pagar uma escola particular ele coloca o filho na pública. (ENTREVISTADA 1)

Eu já trabalhei em escola particular como eu trabalhei na pública e é tão difícil; não posso dar uma opinião generalizada. Temos escolas particulares boas e ruins assim como temos escolas públicas boas e ruins, mas geralmente a escola particular é melhor. As minhas duas filhas fizeram o fundamental na pública e o médio na particular. Eu tenho um filho hoje que estuda na escola particular, mas se tivesse trabalhando no mesmo horário que ele faria na escola pública o ensino fundamental, mas o médio na escola particular por que aqui ele, o ensino médio, está defasado. [...]. Primeiro a escola pública tem que melhorar para colocar meus filhos nela. Eu ficho chateada porque colocam a culpa só no professor e não é só ele que vai mudar; às vezes fazemos para os filhos o que os pais deveriam fazer. Eu sou otimista. (ENTREVISTADA 25)

\section{d) A importância do Projeto Político Pedagógico}

Também questionamos os professores sobre a importância do projeto político pedagógico como contribuição à qualidade da educação. Os professores foram consensuais ao afirmarem que o Projeto Pedagógico é imprescindível para os rumos da escola, para oferecer as linhas e diretrizes a serem seguidas. Este projeto, em grande parte das escolas investigadas, foi concebido mediante mobilização coletiva de professores.

Como relatado pelos próprios professores, o projeto é um parâmetro, "algo em que você pode se apoiar para seguir e dar continuidade ao trabalho". Afirmam que grandes melhorias na escola foram conseguidas por meio desse projeto da integração, melhorando, consequentemente, o nível dos alunos.

Todavia, também evidenciam que o processo de produção do Projeto, apesar da "autonomia" atribuída ao coletivo docente, ainda ocorre de forma verticalizada, ou seja, com base em exigências determinadas pelas Secretarias de Educação, inspetores e diretores de escolas. Os professores apontam para a necessidade de operacionalizar o Projeto Político Pedagógico na sala de aula e no trabalho cotidiano do professor.

Imprescindível. Com ele sentimos os anseios da comunidade escolar que vamos trabalhar, quais as competências dos nossos professores para atender essa clientela e o que tiver faltando nós buscaremos outros meios. (ENTREVISTADO 12)

Sim, ele dá uma direção para o professor que chega na escola, ele direciona o caminho que queremos seguir. (ENTREVISTADA 21)

$\mathrm{Eu}$ acho que é importante em tudo que você vai fazer; com algum prefeito, nos podíamos escolher o diretor, e no seu segundo mandato trabalhamos muito com um projeto. Ele é muito importante; sem ele, ficamos perdidas, pois lá está nossa filosofia de trabalho. (ENTREVISTADA 23)

e) a contribuição dos métodos pedagógicos para a qualidade da educação

Em relação às teorias e métodos pedagógicos adotados na sala de aula, quando questionados se existem métodos mais eficientes para contribuir para a melhoria da qualidade da educação, verificamos que métodos os mais diversos são utilizados e adaptados aos contextos de cada sala. 
Um método seria o professor ser bastante estudioso e sistematizar o ensino porque muitas vezes ele não tem o objetivo traçado, muitos professores não têm um método para seguir, temos que traçar uma meta. O nosso método é pegar o tradicional misturado com o moderno, fazer o aluno pensar no que está fazendo. E também diversificar a abordagem. (ENTREVISTADA 25)

Segundo os professores, não existe receita, nem métodos apropriados todos trazem vantagens e desvantagens, vai depender da turma e do local, talvez um método que funcione para uma turma não funcione para outra turma da mesma escola. Fatores como a realidade dos alunos e o interesse devem ser levados em conta; não existe um método pronto ou um mais eficiente, pois cada criança é única, o que mais funciona é aquele que melhor se adapta ao que você tem na sala de aula.

Contribuem. Não existem métodos apropriados, pois todos trazem vantagens e desvantagens; então, você tem que ter consciência da situação em sala para ver qual método você vai ter que usar com ele. Tem que conhecer todos os tipos de método, quais as vantagens de um e de outro e as desvantagens, e ver como seu aluno reage diante do método que você adota. Trabalhar tentando usar todos os métodos possíveis para atingir seu aluno (ENTREVISTADA 7)

f) a colaboração família-escola

No que se refere à colaboração família-escola, os professores apontam uma omissão por parte de algumas famílias. Especialmente nas escolas públicas, onde os professores relatam haver um descaso por parte dos pais, a educação dos filhos tem sido entregue aos professores. Este não é mais reconhecido como aquele profissional responsável por transformar a criança em um cidadão.

Já na escola particular, a relação que tem se desenvolvido entre escola e pais é uma relação de clientela, de "terceirização" dos filhos como relatam alguns professores. O professor é tratado como uma babá, um tomador de conta e, ao contrário do que ocorre na escola pública, na rede privada os pais estão mais presentes cobram mais, pois estão pagando por um serviço e querem ver o retorno. Conforme relato de uma professora de 45 anos que tem 18 anos de experiência no magistério,

nós estamos vivendo um tempo assim, em que de que a escola esta desempenhando papel muito importante na educação das crianças; então, os filhos são terceirizados. As escolas [é] que têm tomado conta, então; assim, as famílias queixam porque não têm tempo porque trabalham muito; isso. em todo canto acho que isso nas públicas também é realmente... é assim quem ganha pouco está numa luta muito grande e realmente se ausenta muito de casa; os meninos estão mais soltos. (ENTREVISTADA 9)

g) A imagem e o reconhecimento da profissão de professor

Indagamos sobre o reconhecimento dos professores na sociedade atual. Foi unânime entre os professores a opinião de que esses profissionais são muito desvalorizados, o professor sendo tratado como sofredor e sua profissão uma 
"profissãozinha". Há uma imagem negativa da profissão; quando alguém se identifica como professor já carrega consigo uma carga emocional de pessoa cansada, que recebe pouco, sem opção e que não tem status social.

Acho que é vista como uma profissãozinha, que não tem uma grande importância, que ela não está a altura de um médico de um [...] cirurgião qualquer aí, então é isso, é uma profissão que está a menos assim ... e isso tem haver com ... assim, eu acho que é uma profissão que não é tão bem paga [...] o salário já discrimina o profissional no mercado; então, nesse sentido, eu acho que não receber assim ..., é também, eu acho que já determina uma discriminação na profissão.

Os professores com mais experiência no magistério relatam que, com o passar dos anos, viram cair o valor social do professor. Se há vinte anos formar-se professor era tão digno e reconhecido, hoje, como relatado por uma professora da rede estadual de ensino, as pessoas dizem: "Coitado mas você vai ser professor? Que é isso? Você vai sofrer demais! Aproveita! Muda! (ENTREVISTADA 7).

Quem tem a intenção de ser professor está sendo motivado a escolher outra profissão, pois, como relata a professora, ser professor não dá para ficar rico. $\mathrm{O}$ professor vai ter dificuldades financeiras.

Na percepção dos entrevistados o professor é visto como responsável por tudo; desde educação do berço até a formação final do aluno. A impressão é de que a família entregou o filho para eles tomarem conta, educar, como podemos ver nos depoimentos que se seguem:

A sociedade hoje tem uma visão assim: ele é professor.... um cidadão comum sem importância nenhuma. Na nossa comunidade, o professor está comparado a um serviçal qualquer; a única função nossa é educar o filho; se a gente educou bem, a gente tem um valor sim. Se a gente conseguiu fazer aquele aluno aprender alguma coisa, levou ele a um nível elevado de aprendizagem, a gente até tem valor, mas se aquele aluno que não tem vontade, não tem nada, agente não tem valor; a culpa é nossa que não conseguiu. (ENTREVISTADA 2)

Na sociedade, os professores são muito desvalorizados; quando você vai sentar numa roda para conversar, nossa! Mas você é professora? Parece que está nadando contra maré. Nossa! Mas não teve outra oportunidade de trabalho? Você não quis outra formação? Nossa! Então você queria era nada com a dureza. Você não procurou outro caminho foi por um mais fácil de dar aula. Foi por isso que você fez pedagogia, então? Curso de espera marido, você escuta muito essas coisas. (ENTREVISTADA 8)

Alguns relatos demonstram que os professores não se sentem bem em dizer que são professores, pois, até no próprio círculo familiar o professor tem sido desvalorizado, especialmente quando comparado a outros profissionais. Além disso, os professores entrevistados relatam que os próprios alunos não valorizaram nem respeitam o professor.

Ao perguntarmos sobre a existência da relação entre o salário do professor e a educação que ele oferece e qual seria o salário justo para o trabalho que ele desempenha, percebemos que a insatisfação com a remuneração do professor é geral entre os entrevistados. 
Em média, o salário dos professores na rede municipal e estadual de ensino no Estado de Minas Gerais é de R \$ 870,00 e na rede particular R \$ 1.100,00. Já na rede municipal no Estado de Goiás os professores da zona rural recebem cerca de $\mathrm{R} \$ 1.400,00$ para trabalharem trinta horas semanais.

Os professores investigados consideram que o salário pago aos professores é baixo, fato o que os obriga, na grande maioria dos casos, a ocupar dois cargos, a dobrar a jornada de trabalho e até ter um bico para conseguir sobreviver. O que recebem só permite ter as mínimas condições de sobrevivência. Fatores que acabam afetando a qualidade do ensino que oferecem.

Um dos professores entrevistados, que há dez anos trabalha na rede estadual de ensino, quando questionado sobre a relação salário e qualidade da educação oferecida afirma que

Existe muita relação, é a principal. Prá se cobrar alguma coisa, tem que oferecer. O nosso governo atual ta cobrando muito, mas não oferece, não paga bem seu profissional. O profissional, para não ter um salário muito baixo, tem que ter dois cargos, e dois cargos não funcionam para a pessoa trabalhar 36 aulas. Então, o certo seria o professor ter um cargo, ficar o dia todo na escola para recuperar os alunos, [e o governo] pagar melhor o profissional professor. (ENTREVISTADO 3)

Os professores relatam que tem havido muita cobrança por parte do governo, mas sem nenhuma contrapartida financeira. As condições de trabalho dos professores na escola têm sido cada vez mais pioradas; cada vez mais, a responsabilidade do sucesso ou insucesso escolar tem sido atribuída ao professor; entretanto, não têm sido criadas as condições necessárias para o desenvolvimento de seu trabalho na escola. São cobrados diariamente para se atualizarem, para buscar novos caminhos a fim de melhorar a qualidade de seu ensino, mas desde que seja por sua conta.

Um salário justo, segundo os professores entrevistados, seria aquele que desse para manter a família, oferecesse condições de se comprar uma casa, comprar livros, sair para fazer cursos fora, que permitisse ter um plano de saúde e alguma forma de lazer.

Alguns entrevistados são mais incisivos ao apontarem que os professores deveriam ganhar como outros profissionais, como médicos, juízes e até deputados e questionam a inexistência de um órgão, como um conselho, que poderia ajudar a melhorar as condições salariais dos professores.

h) As prioridades para a melhoria da educação pública

$\mathrm{Na}$ última questão da entrevista solicitamos aos professores que citassem, por ordem de prioridade, algumas medidas que garantiriam uma educação de qualidade para todos. Dentre as medidas que aparecem como prioritárias nos discursos dos professores para melhorar a qualidade da educação, estão: a valorização do professor, melhores salários e mais investimentos na escola.

O que os professores objetivam ao indicar essas prioridades é: ter condições mais dignas para a realização dos seus trabalhos; mais investimentos na formação inicial e continuada; possuir mais reconhecimento social; acabar com as jornadas duplas de trabalho e contar com a possibilidade de dedicar-se integralmente a um único cargo. 
Além dessas prioridades citadas, a colaboração dos pais com a escola também foi bastante ressaltada. Os professores têm buscado um maior envolvimento da família com a escola e almejam que os pais participem mais ativamente da educação dos filhos, incentivando-os a estudar em casa e oferecendo-lhes suporte nos momentos extraclasse. Manifestam, ainda, a expectativa de que a educação dos estudantes não fique entregue somente aos professores.

\begin{abstract}
A primeira coisa seria salário para dar competência à família e ter tempo disponível de pesquisa e preparação para sua aula. A escola quer uma prova digitada e os professores não têm tempo nem equipamento para fazer seu material. A escola oferece o espaço, mas não temos tempo fora do nosso horário para ir lá. O principal seria, o meu sonho seria apoio moral, financeiro, e acompanhamento da família e da população. (ENTREVISTADA 12)

Em primeiro lugar, seria o investimento na formação de professores, em seguida, recursos materiais de acordo com o desejo e a dificuldade de cada aluno, recursos humanos para trabalharmos melhor aqui, precisamos mais de professores, da colaboração dos pais para incentivarem as tarefas de casa e da melhoria do nosso salário para sermos mais motivados. (ENTREVISTADA 25)

Que os investimentos na educação fossem verdadeiros. O dinheiro que o Estado diz que passa, chegar realmente na escola. Trabalhei numa escola ha dez anos atrás, eles fizeram um laboratório de informática e gastaram muito dinheiro, uma casa que a minha família fez, muito boa, foi o que eles gastaram para reformar uma sala de informática!! O dinheiro que for destinado à educação realmente vá para a educação. (ENTREVISTADO 28)
\end{abstract}

\title{
CONSIDERAÇÕES FINAIS
}

Com as reformas educacionais desencadeadas a partir dos anos de 1990, os professores têm sido muito visados pelos programas dessas reformas enquanto agentes centrais da mudança e, muitas vezes veem-se constrangidos ou cobrados injustamente por sua responsabilidade, pelo êxito ou insucesso dos programas educativos. Por outro lado, as medidas de natureza econômico-administrativa, que têm por objetivo a racionalização dos serviços e o controle dos gastos, relativos à gestão de pessoal na área pública, têm exercido grande influência nas condições de trabalho dos professores, no funcionamento das escolas e na organização pedagógica.

As mudanças na organização escolar têm representado grande sobrecarga de trabalho para os professores. O acompanhamento e o controle do processo de aprendizagem dos alunos têm requerido maiores cuidados, novos conhecimentos e habilidades, exigindo um tempo de trabalho, que está além da jornada semanal remunerada. (OLIVEIRA, 2008)

Por meio das entrevistas realizadas neste estudo, verificamos que os professores são cobrados pela melhoria da qualidade da educação. Entretanto, as condições de trabalho proporcionadas para os professores não correspondem às suas reais necessidades para o desenvolvimento de um trabalho de qualidade na escola e estes, muitas vezes, vêem-se sozinhos para a realização dessa importante tarefa.

A análise das entrevistas tornou evidente também uma contradição. No âmbito da escola, exige-se dos docentes, atualização, disposição e adaptação para enfrentarem e 
se adequarem às mudanças. Todavia, não lhes são proporcionadas as condições para que isso se efetive. A formação, na grande maioria dos casos, fica sob a responsabilidade do próprio professor, que, com seu salário reduzido, tem que dar conta de sobreviver e manter-se atualizado.

Como aponta Oliveira $(2005,2008)$, tem ocorrido uma regulação sobre o trabalho dos professores sob formas cada vez mais sutis por parte dos gestores dos sistemas centrais de ensino; os "pacotes educacionais", as tecnologias pedagógicas, os livros didáticos; os calendários, horários e as diversas modalidades de supervisão de seu tempo e trabalho. O professor responde a instâncias hierárquicas de gestão e também a pressões internas por parte da direção e da coordenação da escola e dos pais dos alunos. Os mecanismos de controle constituem-se em critérios para avaliação do desempenho institucional e individual. Os resultados das avaliações determinam os salários, as progressões na carreira, a intervenção para corrigir desvios e até a dispensa de pessoal.

A intensificação do trabalho na escola com o acréscimo de tarefas, projetos, atividades, disciplinas, conteúdos, carga horária e programas, o excessivo número de alunos em sala de aula - somados às várias turmas, os turnos e as escolas onde lecionam - desgastam os professores e exaurem suas energias. Estes ficam impossibilitados de refletir sobre o sentido e o andamento de sua prática, o que compromete a qualidade de seu trabalho.

A forma que os professores têm encontrado para aumentar os seus salários é a ampliação da jornada de trabalho. Eles passam a ministrar aulas em dois turnos diferentes e até mesmo em três, em uma ou mais de uma escola. Grande parte dos professores entrevistados adere a essa prática. O cansaço derivado do excesso de trabalho, além de trazer conseqüências para o andamento do trabalho pedagógico, também produz efeitos na saúde dos professores, que apontam como os principais males que os afligem o cansaço físico e mental, esgotamento, dor de cabeça, dor nas pernas, nos ombros, na coluna, irritação na garganta, rouquidão, insônia, frustração, angústia e ansiedade. (OLIVEIRA, 2008; GARCIA e ANADON, 2006)

A autonomia da escola decorrente dos processos de descentralização, traz consequiências drásticas para os trabalhadores docentes. Com ela, os professores ganham maior autonomia e liberdade de definir certas regras do seu dia-a-dia, como o calendário, a escolha de um tema transversal a ser trabalhado por toda a escola, a definição de projetos, a discussão coletiva de saídas e estratégias para desafios encontrados localmente, a busca de recursos para além dos ordinários. Mas, ao mesmo tempo, os trabalhadores docentes tornam-se mais presos a suas atividades $\mathrm{e}$ compromissos. A responsabilização sobre os destinos da escola, dos alunos, dos projetos passa a ser cada vez maior. É como se os trabalhadores docentes tivessem que pagar o preço por essa autonomia conquistada, já que resultante de suas lutas. (OLIVEIRA, 2008)

Fica evidente nas falas dos professores que não se pode pensar em qualidade da educação básica sem pensar na melhoria das condições de trabalho dos professores, em sua valorização, em salários mais dignos que permitam uma formação constante. Pensar em qualidade da educação requer que recursos humanos e materiais sejam providos às escolas; que estas recebam mais investimentos por parte dos governos e que as famílias acompanhem de perto a educação de seus filhos. 


\section{ABSTRACT}

This article gives an overview of the findings of a joint research project undertaken by HEPBEJUNE and different Brazilian institutions. We begin by analyzing the national and international context within which basic education in Brazil is situated. Next, we explore the use of the notion of quality in education. Finally, we present some of the findings of fieldwork carried out with public school teachers in the states of Goiás and Minas Gerais.

Keywords: Basic education. Quality. Teachers. Public schools.

$1 \quad$ NOTAS

$\square$ Organização das Nações Unidas para a Educação, a Ciência e a Cultura; Fundo das Nações Unidas para a Infância e Programa das Nações Unidas para o Desenvolvimento respectivamente.

2 Conforme nota do INEP, as escolas que não apresentam IDEB enquadram-se nas seguintes situações: a) escolas particulares, escolas rurais, [...] bem como escolas públicas com menos de vinte alunos matriculados nas series avaliadas ( $4^{\mathrm{a}}$ série $/ 5^{\circ}$ ano e $8^{\mathrm{a}}$ série $/ 9^{\circ}$ ano), conforme declaração prestada ao Censo escolar 2006; b) escolas pertencentes a redes municipais que não aderiram à Prova Brasil, cuja participação não foi obrigatória,uma vez que a média na Prova é componente do cálculo do IDEB e c) escolas em que menos de dez alunos compareceram à avaliação, visto que, do ponto de vista metodológico, isso não refletiria o resultado de toda a escola.

\section{REFERÊNCIAS}

BRASIL. Lei $n^{\circ}$ 9.394, de 20 de dezembro de 1996. Estabelece as diretrizes e bases da educação nacional. Disponível: http://www.mec.gov.br.

CONFEDERAÇÃO NACIONAL DOS TRABALHADORES EM EDUCAÇÃO. Retrato da escola II. Brasília, DF: CNTE, 2001. Disponível em: <www.cnte.org.br> Acesso em: 2005.

\section{CONFEDERACIÓN DE TRABAJADORES DE LA EDUCACIÓN DE LA} REPÚBLICA ARGENTINA (CTERA). et al. Las reformas educativas en los países del Cono Sur: un balance crítico. Buenos Aires: CLACSO, 2005.

ESTADO DE MINAS GERAIS. Secretaria de Estado da Educação. SICA Sistema Informacional Custo-Aluno. Média custo-aluno na rede estadual, por regional. Belo Horizonte: SEE, 2002.

FREITAS, H. C. L. A reforma do Ensino Superior no campo da formação de profissionais da educação básica: as políticas educacionais e o movimento dos educadores. Educ. Soc. Campinas, v. 20, n. 68, dez 1999. Disponível em: <www.scielo.br $>$. Acesso em: 21 de set. 2004

Formação de Professores no Brasil: dez anos de embates entre projetos de formação. Educ. Soc, Campinas, v. 23, n. 80, set. 2002. Disponível em: <http://www.scielo.br/scielo $>$. Acesso em 10 out. 2004. 
GARCIA, M. M. A.; ANADON, S. B. Reforma educacional, intensificación del trabajo docente, cuidado y género. In: FELDFEBER, M.; OLIVEIRA, D. (comps.). Políticas educativas y trabajo docente: Nuevas regulaciones ¿ Nuevos Sujeitos?. Buenos Aires/México: Noveduc. 2006, p.181-204.

OLIVEIRA, D. A. Regulação Educacional eTrabalho Docente: mudanças na gestão dos sistemas e das escolas. In: Conferência Internacional "Educação Globalização e Cidadania: novas perspectivas da Sociologia da Educação". João Pessoa, 2008.

. A reestruturação do trabalho docente: precarização e flexibilização.

Educação e Sociedade. Campinas, v. 25, n. 89, set/dez 2004. Disponível em: <www.cedes.unicamp.br>. Acesso em: 15 de Ago. 2006.

. Regulação das políticas educacionais na América Latina e suas conseqüências para os trabalhadores docentes. Educação e Sociedade. Campinas, v. 26, n. 92, out. 2005. Disponível em: 〈www.scielo.br〉. Acesso em: 22 de Ago. 2006.

. (org.). Reformas Educacionais na América Latina e os trabalhadores docentes. Belo Horizonte: Autêntica, 2003.

PACHECO, E; ARAÚJO, C. H. Pesquisa Nacional Qualidade da Educação: a Escola Pública na opinião dos pais. Brasília: Instituto Nacional de Estudos e Pesquisas Educacionais Anísio Teixeira, 2005.

Abdeljalil Akkari é professor na Haute École Pédagogique, BEJUNE e na Universidade de Genebra (Suíça), É doutor em Ciências da Educação pela Université de Géneve, Genebra-Suiça.

Rossana Valéria Souza Silva é Professora Adjunto 4 da Universidade Federal de Uberlândia, doutora em Educação pela Unicamp, com Pós-Doutorado em Ciências da Educação na Université Paris 8, Paris-França.

Ana Sheila Fernandes Costa é Master Internacional no Istituto Universitario di Scienze Motorie IUSM (Roma/Itália) e Mestre em Educação pela Universidade Federal de Uberlândia. 